\title{
Divine Love and Deep Connections: A Long-Term Followup of Patients Surviving Cardiac Surgery
}

\author{
Amy L. Ai ${ }^{1}$ and Daniel E. Hall ${ }^{2,3}$ \\ ${ }^{1}$ Department of Family Medicine, School of Social Work, University of Pittsburgh, 2028 Cathedral of Learning, \\ 4200 5th Avenue, Pittsburgh, PA 15260, USA \\ ${ }^{2}$ Center for Health Equity Research and Promotion, VA Pittsburgh Healthcare System, 7180 Highland Drive (151 C-H), \\ Pittsburgh, PA 15206, USA \\ ${ }^{3}$ Department of Surgery, University of Pittsburgh, Suite F1264, 200 Lothrop Street, Pittsburgh, PA 15213, USA
}

Correspondence should be addressed to Amy L. Ai, amyai8@gmail.com

Received 11 January 2011; Revised 3 March 2011; Accepted 19 March 2011

Academic Editor: J. Woo

Copyright (C) 2011 A. L. Ai and D. E. Hall. This is an open access article distributed under the Creative Commons Attribution License, which permits unrestricted use, distribution, and reproduction in any medium, provided the original work is properly cited.

\begin{abstract}
We examined experiencing divine love as an indicator of affective spiritual growth in a prospective cohort of 200 patients surviving cardiac surgery. These patients previously completed two-wave preoperative interviews when standardized cardiac surgery data were also collected. The information included left ventricular ejection fraction, New York Heart Association Classification, baseline health (physical and mental), optimism, hope, religiousness, prayer coping, religious/spiritual coping, and demographics. We then measured divine love at 900 days postoperatively. Hierarchical linear regression indicated the direct effect of positive religious coping on experiences of divine love, controlling for other key variables. Postoperatively perceived spiritual support was entered at the final step as an explanatory factor, which appeared to mediate the coping effect. None of the other faith factors predicted divine love. Further research regarding divine love and spiritual support may eventually guide clinical attempts to support patients' spiritual growth as an independently relevant outcome of cardiac surgery.
\end{abstract}

\section{Introduction}

Severe cardiovascular disease (CVD) is a condition that constitutes the highest mortality in the United States (US) [1]. Cardiac surgery is a life-saving operation for many with advanced heart conditions. However the risk of perioperative death is real, and it is most acute for those with heart failure or advanced age. As such, surgeons routinely inform patients of the possibility of death due to surgery-related complications. The life and death stakes in these circumstance makes an existential challenge inevitable, and survival from such experiences can pave a way to spiritual growth [2]. The present study explored experiencing divine love, as a form of personal growth or spiritual transformation, in a longterm followup of patients who survived cardiac surgery and participated in a two-wave preoperative study [2].

For decades behavioral health research has focused primarily on pathology and negative affect traits (e.g., depression, pain) as indices of recovery from life-threatening conditions. This symptom reduction refers to the concept of subjective well-being (SWB, the hedonic tradition), in contrast to that of psychological well-being (PWB, the eudaimonic tradition) in light of positive psychology that focus on the positive side of life even in adversity [3]. The latter especially involves personal growth after trauma, such as worldview alteration (e.g., meaning in life, enhanced relations). Thus, experiencing divine love after surviving cardiac surgery can be viewed as an affective form of PWBrelated spiritual growth. As a potential protector for health and mental health, love is generally defined as positive affect plus absence of social isolation $[4,5]$. In contrast to the love shared through relationships between human beings, divine love refers to loving God or love received from God, the Absolute or Higher Power [4, 6-8]. Post [9] has written extensively on this topic in relation to historical concepts in mainstream religions (e.g., agape, universal love, altruistic 
love, and unlimited love). Sociologist Sorokin [7] had indepth elaboration on religious love in light of spiritual growth.

Divine or religious love is a kind of spiritual positive affect. Evidence has linked positive affect with adaptive coping in response to crises $[10,11]$, which was predictive of cardiovascular recovery following anxiety-producing situations [12]. In line with the positive-affect dimension, Levin $[13,14]$ associated religious love with better subjective health and lower distress in a sample of 205 outpatients. No study, however, has examined divine love as a long-term PWB outcome in cardiac surgery patients. Exploring this form of growth is important in the face of such an existential challenge, given that, in general, positive psychology has endorsed a positive dimension in life [15]. More specifically, Ai and colleagues argue that the heart is a mystified meaningladen organ in human history and is symbolically related to the sense of love in many cultural legacies, including Western religions, in particular [16]. Van Lommel et al.'s [17] review of near death experiences in patients revived from cardiac arrest suggested spiritual transformation of most survivors. Despite a different mechanism, cardiac surgery often requires cardioplegia (temporarily stopping of the heart), during which time the patient is kept alive using a heart-lung bypass machine. Accordingly, the experience of cardiac surgery and its attendant cardioplegia may be an occasion for spiritual transform similar to that described by survivors of cardiac arrest. Divine love may be an indicator for spiritual growth or transformation in the aftermath.

Our first research question concerned which of religious factors measured preoperatively would stand out as stronger predictors of divine love. We assessed divine love with a Religious Love subscale by Levin and Kaplan [18] which indicates experiencing God's love and conviction of the infinite nature of such love. To be more inclusive, we instructed our respondents to "replace the term 'God' with the 'Deity/Deities' or 'A Higher Power' pertaining to your spiritual or religious beliefs." However, we did acknowledge that the concept of divine love may be more predominant in those religious traditions that conceive God personally (e.g., Christianity, Judaism, or Islam) when compared to traditions with impersonal (or even secular) concepts of deity or "higher power" [19]. Love, with hope and faith, is an abiding Christian characteristic in the New Testament (I Corinthians 13:13), Given the central role of love in Christianity, experiencing divine love would likely be especially important for our mainly Christian sample (86\%) [20]. We thus anticipated that certain preoperative religious factors would predict experiencing divine love.

In particular, we hypothesized that preoperative religious coping would predict experiencing divine love, above and beyond existing predictors (e.g., demographics, health and mental health-related risk, and protective factors) [20]. Out of multifaceted faith factors, one behavioral measures is particularly worth noting: Frankl [21] asserted that "meaningful actions" were essential to people confronted with severe threats. Reaching out to God (or higher powers) for help is seen as a form of "meaningful action" in the face of a life-changing event. Pargament [22] identified two styles of religious/spiritual coping. Positive spiritual coping involves positive faith-based approaches (e.g., turning toward God and searching for significance; p. 46) whereas negative spiritual coping involves faith-based struggles and doubt (e.g., questioning about or turning anger toward God) [23]. A meta-analytic review linked positive spiritual coping with positive outcomes and negative coping with negative outcomes [24]. In an earlier study of our sample, we found similar associations between the two styles of religious coping and short-term postoperative adjustment to cardiac surgery (e.g., those with positive religious coping had less negative affect one month postoperatively, and those with negative religious coping had more negative affect). However, only positive spiritual coping mediated the indirect effect of general religious involvement on negative affect [25]. Accordingly, we hypothesized that religious/spiritual coping measured before the operation would predict the postoperative experience of divine love, and that positive and negative coping styles would influence the experience of divine love in opposite directions. Furthermore, according to a 17th century rabbi, "Prayer is God's gift of love" [26, 27]. Based on data demonstrating that lower levels of negative affect were associated with using prayer for coping [20], we also hypothesized that preoperative use of prayer for coping would predict postoperative perception of divine love.

Our second research question addressed the possible mechanism for our hypothesized effect of religious/spiritual coping [28]. According to Baron and Kenny [29], if the effect of predictors on outcomes vanishes to zero after controlling for the correlated mediator, then the latter factors explain the indirect effect of the former predictors. Spiritual connectedness has been taken as a component in various concepts of spirituality $[7,30]$ or as the key of its definition. According to Pargament [31, page 34], deep connection with the sacred is at the core of understanding faith-based life [31, page 34]. In this light, we expected that cardiac surgery patients who used religious/spiritual coping preoperatively would be more likely to perceive spiritual connectedness postoperatively, and this connectedness might, in turn, influence the affective spiritual growth at the followup. To assess the possible mediating influence of latent spiritual connectedness, Ai et al. $[19,32]$ developed a scale, termed "perceived spiritual support," to measure the perception of multifaceted support from "a deep connection with a higher power or a spiritual relationship in a faith" $[19,32]$. In samples of nonmedical subjects, perceived spiritual support was shown to mediate the effect of faith and prayer coping on such positive outcomes as optimism and posttraumatic growth (PTG) [19, 32]. Accordingly, we hypothesized that the postoperatively perceived spiritual support would mediate or explain the hypothesized effect of preoperative religious/spiritual coping on divine love.

\section{Method}

2.1. Procedures. The study was conducted at the Heart Center of the University of Michigan Health Systems (UMHS, Ann Arbor). The Section of Cardiac Surgery, UMHS, is a 
specialty center for valve surgery in heart failure management with many severe cases referred from other hospital settings. The patient pool thus contains more advanced heart conditions, especially congestive heart failure (CHF), than would be found in typical surgery units. Participants were a convenience sample of patients who completed a mailed survey 30 months after surviving nonurgent and nontransplant cardiac surgery at the University of Michigan's Medical Center (UMMC). Cardiac data were obtained from the Society of Thoracic Surgeons' (STS) national database.

For the previous short-term, three-wave survey, cardiac surgeons delivered the information package about this study $[26,27]$. Participating patients consented to three sequential interviews. The first wave of interviews was conducted by trained interviewers and assessed demographics, religious affiliation, religiousness, medical comorbidities, and mental health symptoms (depression) two weeks before surgery. The second wave via telephone assessed psychosocial protectors (optimism, hope, and social support) and religious coping styles approximately 48 hours before surgery.

The current study reports results from the additional contact at 30 months postoperatively with the 335 patients who survived surgery and also responded to this request for long-term followup [20]. This third contact was a new study supported by a different grant. Attrition at this long-term followup was mostly due to mortality, outdated contact information, or patient refusal to participate. A computerized double-entry system was used for data entry to ensure high quality.

2.2. The Sample. Eligibility criteria for the initial sample were as follows (a) aged 35 years or older; (b) scheduled for admission for nonemergency, nontransplant cardiac surgery (e.g., coronary artery bypass grafting (CABG), aneurysm repair, and valve repair/replacement), requiring cardiopulmonary bypass; (c) able to speak and understand English; (d) cognitively and physically capable of providing informed consent.

The details of the initial sample, recruited for the previous these survey, including percentages of religious involvement, were reported elsewhere [2]. For demographics, the majority were male (60\%), white (92\%), and married with spouse present $(76 \%)$. Average age was 62 years $(\mathrm{SD}=$ 11.7, range, 35-85). Among patients who were asked a question concerning whether or not they had their affairs in order one-month postoperatively, 273 (81\%) answered affirmatively [33]. Respondents who indicated "yes" to having their affairs in order were given the opportunity to specify the type of arrangements. Among the 355 participants who provided open-ended answers, the majority $(65 \%)$ indicated that they had a legal document such as a will, a trust, and/or living will. But, only a small number noted that they had provided instructions to family members (5\%) or specified funeral arrangements (3\%). A few respondents (7\%) specified spiritual arrangements, such as "asked for certain Bible messages to be read at funeral," "peace with myself and God," or "blessed prior to surgery."
2.3. Baseline Cardiac Health. Cardiac and surgical data were retrieved from the STS database. For this subsequent analysis, left ventricular ejection fraction (LVEF) was used to measure preoperative cardiac function. LVEFs were derived from preoperative catheterization and angiography, indicating the percentage of blood emptied from the ventricle at the end of cardiac contraction. In this sample, the mean value was $51.56 \%(\mathrm{SD}=14.20)$. New York Heart Association (NYHA) Classification ranks the extent of heart failure from I (no limitation of ordinary activity) to IV (severe symptoms even at rest, mostly bedbound). For this sample, the highest level for each patient was recorded with the following distribution: Level I $=39.3 \%$, II $=34.7 \%$, III $=23.7 \%$, IV $=1.5 \%[20]$.

2.4. Preoperative Psychosocial Measures. Demographics included age (years), gender (male, female), race (white, other), and marital status (married with spouse present or living with significant other, and other).

Preoperative Depression was assessed with the 20-item Center for Epidemiologic Studies Depression Scale (CES-D) [34] with individual items scored on a 4-level Likert scale $(M=11.84, \mathrm{SD}=9.10, \alpha=.88)$.

Perceived Social Support was assessed with the 12-item Multidimensional Scale of Perceived Social Support (MSPSS) [35], measuring perceived support from family, friends, and significant others, with individual items scored on a 4-level scale $(M=61.54, \mathrm{SD}=8.59, \alpha=.89)$.

Optimism was assessed with the 12 -item Life Orientation Test (LOT) [36]. Patients were asked about the extent to which they agree with each statement in the prior month on a 5-level scale (preoperative: $M=22.19, \mathrm{SD}=4.46, \alpha=.73$ ).

Hope was assessed with the 12-item Hope scale [37], which asks participants to report how they felt about each statement in the prior month on a 5-level scale (preoperative: $M=31.06, \mathrm{SD}=4.31, \alpha=.81$ ).

Religiousness was assessed with the 11-item Religiosity Scale [38] which measures: public religiosity $(M=11.28$, $\mathrm{SD}=4.60, a=.87)$, private religiosity $(M=10.06, \mathrm{SD}=$ $3.86, \alpha=.78)$, and subjective religiosity $(M=5.98, \mathrm{SD}=$ $1.71, \alpha=.88)$.

Prayer coping was assessed with the 3-item Using Private Prayer for Coping index [39]. Patients were asked the extent to which they agreed with each of the following statements: (a) "Prayer is important in my life"; (b) "Prayer does not help me to cope with difficulties and stress in my life" (reversescored); and (c) "I will use private prayer to cope with difficulties and stress associated with my cardiac surgery." All questions were scored on a 4-level scale $(M=9.97$, $\mathrm{SD}=2.44, \alpha=.89$ ).

Religious/Spiritual Coping styles was assessed with the 14-item Brief Religious/Spiritual Coping Scale (R-Cope) [40], with seven items each for positive and negative styles. Patients responded to these items in terms of how they generally coped with stressors rather than with respect to the operation or heart disease. Thus, religious coping was assessed as a dispositional or coping style variable rather than a situation-specific construct. Examples of positive coping include forgiveness, seeking spiritual support, collaborative 
religious coping, spiritual connection, and benevolent religious reappraisal (e.g., "Asked forgiveness for my sins," $M=$ $11.69, \mathrm{SD}=6.45, \alpha=.93$ ). Examples of negative coping include spiritual discontent, punishing God reappraisals, interpersonal religious discontent, and demonic reappraisal (e.g., "Questioned the power of God," $M=1.12, \mathrm{SD}=2.30$, $\alpha=.83)$.

Perceived spiritual support was assessed with the 12item Spiritual Support Scale (SSS) [32], assessing spiritual relationships in diverse beliefs (e.g., "I have been inspired by my religious or spiritual faith in the face of distress"). To be more inclusive, we instructed our respondents to replace God with appropriate terms in their faiths. Respondents stated on a 4-level scale concerning each statement following cardiac surgery $(M=41.57, \mathrm{SD}=14.25, \alpha=.98)$.

Divine love was assessed with the 4-item subscale of the Sorokin Multidimensional Inventory of Love [18], assessing religious love (e.g., "I feel loved by God," "God's love is eternal"). Respondents stated on a 5-level scale concerning each statement at the long-term followup $(M=16.24, \mathrm{SD}=$ $4.18, \alpha=.97)$.

2.5. Statistical Analysis. To test our hypotheses, we conducted serial hierarchical regression analyses following preplanned steps. First, bivariate correlation analyses were conducted using SPSS-18 to determine univariate associations between variables of major interests (including controls) and the outcome (divine love). We then estimated the direct effect of religious/spiritual coping on divine love, controlling for other relevant predictors (e.g., demographics, baseline cardiac health, negative affect, optimistic expectations, and social support). Finally, perceived spiritual support as the mediator was entered at the final step. Predictors were entered into the equation following the predetermined five steps: (1) demographics, (2) baseline cardiac health, (3) selfreported medical comorbidities, psychological symptoms (depression or anxiety), and protectors (optimism, hope, and social support), (4) major religious factors (three-factor religiousness, use of prayer for coping, sense of reverence, and religious/spiritual coping), and (5) a mediator at followup (perceived spiritual support). All tests were two-tailed with significance set at $P<.05$. Collinearity statistics were inspected, using a conservative value of variance inflation factors (VIF) of 4.

\section{Results}

The zero-order correlations of predictors with the outcome show that divine love at the long-term followup was significantly correlated positively with female gender $(P<.001)$ and negatively with $\operatorname{LVEF}(P<.05)$. None of the other factors had significant correlations (e.g., demographics, health and mental health related risk, or protective factors). Of the variables of major interest, not surprisingly, all faith factors except negative spiritual coping were correlated with divine love $(P s .<.001)$.

Results from hierarchical regression analyses predicting perceived love at followup are presented in Table 1. The main effects of preoperative predictors were estimated following the preplanned five steps. The Step 1 model involving demographics accounted for only $5.8 \%$ of the variance but was statistically significant. Only gender was a significant predictor of divine love $(P<.01)$, and female patients were more likely to perceive love than their male counterparts.

Step 2 included LVEF and NYHA classification. It was also statistically significant, accounting for an additional $3.2 \%$ of the variance. The effect of gender found in Step 1 persisted, and LVEF was inversely associated with divine love $(P<.05)$. This indicates that the sickest patients with lower LVEF perceived greater divine love than healthier patients with higher LVEF.

In Step 3, the influence of gender and LVEF on divine love persisted after expanding the model to include preoperative risk and protective factors. No new variables (i.e., selfreported medical comorbidities, preoperative depression, optimism, hope, and social support) were found to be related to divine love. Although the model explained an additional $2.1 \%$ of the variance, this change was not statistically significant.

Step 4 expanded the model to include the variables assessing religiousness. This step was statistically significant, explaining an additional $27.2 \%$ of the variance. The previously described influence of LVEF remained significant, but the gender effect size was completely eliminated. Among all the new variables, only the positive spiritual coping style was associated with divine love $(P<.05)$. The three factors of religiousness (private, subjective, and public), negative spiritual coping, reverence, and using prayer for coping were each unrelated to divine love. Patients reporting positive spiritual coping styles perceived greater divine love at followup.

In the fifth and final step, perceived spiritual support at followup was entered in the equation to determine if it mediated any of the previous predictors. This addition explained an additional $23.9 \%$ of the variance. As expected, perceived spiritual support was positively associated with divine love, indicating that those with higher levels of spiritual support also reported higher levels of divine love. Perceived spiritual support completely eliminated the previously observed influences of both positive spiritual coping and LVEF. No other variables emerged as a predictor. Thus, the effects of positive spiritual coping on divine love appear to be mediated by perceived spiritual support. The model was significant, accounting for $62.2 \%$ of the variance $(F(21$, $\left.N=200)=12.32, P<.001, R^{2}=.622\right)$.

\section{Discussion}

The present study examines how preoperative faith factors predict the postoperative perception of divine love at longterm followup for patients surviving life-altering cardiac surgery. Consistent with our first hypothesis, our data demonstrate that preoperative positive religious/spiritual coping does predict greater levels of experiencing divine love at 30 months after surgery. While an earlier report on this followup found that prayer coping predicted less 
TABLE 1: Regression predicting love.

\begin{tabular}{|c|c|c|c|c|c|}
\hline Variable & $\begin{array}{l}\text { Step 1 } \\
\beta(\mathrm{SE})\end{array}$ & $\begin{array}{l}\text { Step } 2 \\
\beta(\mathrm{SE})\end{array}$ & $\begin{array}{l}\text { Step } 3 \\
\beta(\mathrm{SE}) \\
\end{array}$ & $\begin{array}{l}\text { Step } 4 \\
\beta(\mathrm{SE})\end{array}$ & $\begin{array}{l}\text { Step } 5 \\
\beta \text { (SE) }\end{array}$ \\
\hline Gender & $.228(.155)^{* *}$ & $.251(.159)^{* *}$ & $.273(.165)^{* *}$ & $.080(.157)$ & $.075(.123)$ \\
\hline Age & $.059(.006)$ & $.076(.006)$ & $.064(.007)$ & $-.070(.006)$ & $-.023(.005)$ \\
\hline Race & $-.057(.300)$ & $-.056(.297)$ & $-.072(.303)$ & $-.020(.268)$ & $.029(.211)$ \\
\hline Marital status & $.061(.186)$ & $.068(.184)$ & $.054(.187)$ & $.001(.165)$ & $.048(.130)$ \\
\hline \multicolumn{6}{|l|}{ Step $1 F=2.534(d f=4, P<.05)$} \\
\hline NYHA classification & & $-.103(.094)$ & $-.117(.096)$ & $-.085(.083)$ & $-.028(.065)$ \\
\hline LVEF & & $-.185(.006)^{*}$ & $-.212(.006)^{*}$ & $-.177(.005)^{*}$ & $-.064(.004)$ \\
\hline \multicolumn{6}{|l|}{ Step $2 F=2.678(d f=6, P<.05)$} \\
\hline Medical comorbidity & & & $-.055(.039)$ & $-.013(.035)$ & $-.073(.027)$ \\
\hline Preoperative depression & & & $-.028(.093)$ & $-.066(.080)$ & $.005(.063)$ \\
\hline Preoperative optimism & & & $.093(.170)$ & $.039(.152)$ & $.011(.120)$ \\
\hline Preoperative hope & & & $-.049(.175)$ & $-.084(.154)$ & $-.050(.121)$ \\
\hline Perceived social support & & & $.069(.127)$ & $.042(.115)$ & $.048(.090)$ \\
\hline \multicolumn{6}{|l|}{ Step $3 F=1.784(d f=11, P<.10)$} \\
\hline Prayer coping & & & & $.166(.135)$ & $.076(.106)$ \\
\hline Public religiousness & & & & $-.001(.021)$ & $-.056(.017)$ \\
\hline Private religiousness & & & & $-.092(.028)$ & $-.125(.022)$ \\
\hline Subjective religiousness & & & & $.192(.070)$ & $.040(.056)$ \\
\hline Religious reverence & & & & $.118(.082)$ & $.024(.065)$ \\
\hline Secular reverence & & & & $.037(.057)$ & $.040(.045)$ \\
\hline Positive religious coping & & & & $.242(.114)^{*}$ & $.081(.092)$ \\
\hline Negative religious coping & & & & $.009(.223)$ & $.006(.175)$ \\
\hline \multicolumn{6}{|l|}{ Step $4 F=4.916(d f=19, P<.001)$} \\
\hline Spiritual support & & & & & $.711(.063)^{* * *}$ \\
\hline Step $5 F=12.324(d f=20, P<.001)$ & & & & & \\
\hline
\end{tabular}

negative affect (depression, anxiety) [20], this analysis did not associate this coping strategy with greater positive affect (divine love). Despite the absence of effects from other faith factors, our findings add to the existing data regarding the effect of positive religious coping on a new positive outcome, divine love $[4,6,7,13,14]$ among cardiac-surgery patients who have faced existential issues [2]. In fact, this study may be the first of its kind to use divine love as an indicator of affective spiritual growth or transformation for survival experiences in aging-related severe diseases. Clinically, what remains to be tested is if experiencing divine love is associated with positive physical recovery over time, as demonstrated in other cross-sectional studies $[4,13,15]$.

Unlike the associated pattern between two coping styles and negative affect, as shown in short-term recovery [26, 27], the present study did not support the expected opposite influence of negative religious/spiritual coping on experiencing less divine love. This difference might suggest that, as a positive spiritual affect, divine love is not merely the inverse of negative affect. Unlike the concept of people's love described in positive psychology $[3,15$, page 30$]$, that of divine love, as explicitly noted in the measure [18], highlights its unconditional or unlimited nature $[9,14]$. Divine love is based on an underpinning spiritual outlook in a faith of the divinity, be it God or other Higher Powers [41], which transcends time, space, and human conditions, including the threats of human crises and mortality. In other words, its presence is not conditioned on factors in the physical dimension of life, which often affect or test the quality or quantity of interpersonal love (e.g., presence or fatality of persons involved, health status or resources in the loving context). The conviction of divine love thus can be uniquely reassuring to and existentially meaningful for middle-life and older patients after their survival of cardiac surgery.

Supporting our second hypothesis, postoperatively perceived spiritual support [32] appears to mediate the role of positive religious/spiritual coping on experiencing divine love at followup. Cardiac surgery patients who report positive coping strategies seem to perceive greater levels of spiritual support and greater levels of divine love, and perceived spiritual support seems to mediate the effect of positive religious/spiritual coping on perceived divine love. The finding thus replicate the mediating role of spiritual support in cross-sectional and prospective data from nonmedical settings, such as natural disasters (e.g., Hurricane Katrina; A.L.A., unpublished data, 2010) or political conflicts (e.g., 9/11 terrorist attacks) [19]. A sense 
of deep connectedness refers to the profound relationship with the divine or transcendent that bestow meanings to life [19]. As can be seen as one indicator of this latent spiritual connection, the perceived spiritual support scale essentially measures its resourceful nature, referring to the moment of assessment $[19,32]$.

In general, all these studies have lent further support for the deep connection with the sacred as the key to understanding the core religious life [31, page 34]. The present study, however, shows that perceived spiritual support may particularly reflect cardiac patients' attribution of their survival as the divine's supportive response to their spiritual coping practice, and, as such, it may mediate the effects of that meaningful action on health-related psychological outcomes. Interestingly, the mediating role of perceived spiritual support here is similar to that of social support in both cardiac patients [25] and nonmedial subjects in crisis [19]. Because perceived spiritual support is conceptually different from divine love, it also deserves more quantitative and qualitative investigation in order to better understand its role in the decision making for managing lifechanging medical events such as open heart surgery (A.L.A., unpublished data, 2010) $[19,42]$.

Finally, our analysis found that the positive effect of female gender on perceived divine love vanished when faith factors were added into the equation. This is not entirely surprising because substantial research has repeatedly demonstrated that women score higher than men on most measures of religiousness [43]. Therefore, the initially observed "gender effect" on divine love is likely to be mediated by women's higher levels of religious and spiritual involvement than men. The disappearance of the initial and unexpected impact of low LVEF on experiencing divine love is perhaps more interesting; this vanishing effect did not occur after entry of other faith factors but present at the presence of perceived spiritual support. Indeed, Park et al. [44] found that many scales of faith-related measures, even well validated, were correlated; still, they exerted differential influences on psychological outcomes of cardiac patients. Our previous report has found no correlation between faith factors and this cardiac index [20]; an initial association of LVEF with divine love is thus spurious.

As noted, this study has its limitations, including a convenience sample, racial and religious homogeneity, and attrition of the sample at followup that adds selective bias to healthier and relatively younger survivors [20]. We did not measure divine love preoperatively, nor perceived spiritual support, because both scales had not been created when the study was initiated. Further research may examine how these constructs change over time in other prospective cohorts. Given the central role of love in monotheist religions, divine love, positive spiritual coping, and perceived spiritual support could share this component in assessing faithrelated actions, perceptions, and affective experience, despite distinct conceptual frameworks. The same may be true for other measures of religious involvement (e.g., attending service was, in part, for experiencing the divine). Clearly, these factors were correlated in this sample [20] and so were other faith measures in Park et al.'s [44] study. The issue of commonality warrants future theoretical and empirical study for more conceptual clarity.

Still, the present study contributes to aging and cardiac health literature by examining complexly related concepts important to the spirituality or existential meaning in life of patients surviving cardiac surgery. Although the primary outcome of cardiac surgery is properly focused on cardiac physiology, the recent emphasis on patient-centered or "whole person" medicine insists that cardiac physiology is not the only relevant outcome of cardiac surgery. Indeed, the data discussed here suggest that spiritual growth may be an outcome of cardiac surgery relevant to many patients. As such, health care providers may wish to investigate ways to support patients' spiritual growth in the postoperative period, and this will require better understanding of the pre- and postoperative traits and coping behaviors associated with spiritual growth. Further empirical exploration of divine love in medical contexts may be of major interest for both patients of advanced illnesses and care providers. Given the meaning-laden implications in these concepts, divine love and perceived spiritual support deserve further exploration in research on aging, perhaps especially in the setting of research on PWB after life-changing medical events.

\section{Acknowledgments}

The paper was supported by National Institute on Aging Grant 1 RO3 AGO 15686-01, National Center for Complementary and Alternative Medicine Grant P50 AT00011, a grant from the John Templeton Foundation, and the Hartford Geriatric Faculty Scholars Program. The opinions expressed in this paper do not necessarily reflect the views of these organizations.

\section{References}

[1] American Heart Association, "Heart disease and stroke statistics-2008," 2008, http://www.americanheart.org/downloadable/heart/1200078608862HS_Stats\%202008.final.pdf.

[2] A. L. Ai, C. L. Park, and M. Shearer, "Spiritual and religious involvement relate to end-of-life decision-making in patients undergoing coronary bypass graft surgery," International Journal of Psychiatry in Medicine, vol. 38, no. 1, pp. 113-132, 2008.

[3] S. Joseph and P. A. Linley, "Positive adjustment to threatening events: an organismic valuing theory of growth through adversity," Review of General Psychology, vol. 9, no. 3, pp. 262280, 2005.

[4] J. Levin, "A prolegomenon to an epidemiology of love: theory, measurement, and health outcomes," Journal of Social and Clinical Psychology, vol. 19, no. 1, pp. 117-136, 2000.

[5] A. Walsh and P. A. Walsh, "Love, self-esteem, and multiple sclerosis," Social Science and Medicine, vol. 29, no. 7, pp. 793798, 1989.

[6] J. Levin, "Religion and mental health: theory and research," International Journal of Applied Psychoanalytic Studies, vol. 7, no. 2, pp. 102-115, 2010.

[7] P. A. Sorokin, Explorations in Altruistic Love and Behavior: A Symposium, Beacon Press, Boston, Mass, USA, 1950. 
[8] P. A. Sorokin, The Ways and Power of Love: Types, Factors, and Techniques of Moral Transformation, Beacon Press, Boston, Mass, USA, 1954.

[9] S. G. Post, Unlimited Love: Altruism, Compassion, and Service, Templeton Press, West Conshohocken, Pa, USA, 2003.

[10] B. L. Fredrickson, "The role of positive emotions in positive psychology: the broaden-and-build theory of positive emotions," American Psychologist, vol. 56, no. 3, pp. 218-226, 2001.

[11] B. L. Fredrickson, M. M. Tugade, C. E. Waugh, and G. R. Larkin, "What good are positive emotions in crises? A prospective study of resilience and emotions following the terrorist attacks on the United States on September 11th, 2001," Journal of Personality and Social Psychology, vol. 84, no. 2, pp. 365-376, 2003.

[12] B. L. Fredrickson and R. W. Levenson, "Positive emotions speed recovery from the cardiovascular sequelae of negative emotions," Cognition and Emotion, vol. 12, no. 2, pp. 191-220, 1998.

[13] J. Levin, "God, love, and health: findings from a clinical study," Review of Religious Research, vol. 42, no. 3, pp. 277-293, 2001.

[14] J. Levin, "Is depressed affect a function of one's relationship with God?: findings from a study of primary care patients," International Journal of Psychiatry in Medicine, vol. 32, no. 4, pp. 379-393, 2002.

[15] C. Peterson and M. E. P. Seligman, Character Strengths and Virtues: A Handbook and Classification, American Psychological Association and Oxford University Press, New York, NY, USA, 2004.

[16] A. L. Ai, H. Appel, and J. Pasic, "Mental health comorbidity in cardiovascular disease: implications for interdisciplinary intervention," in Psychological Factors and Cardiovascular Disorders: The Role of Psychiatric Pathology and Maladaptive Personality Features, L. Sher, Ed., pp. 311-338, Nova Science Publishers, Hauppauge, NY, USA, 2008.

[17] P. Van Lommel, R. Van Wees, V. Meyers, and I. Elfferich, "Near-death experience in survivors of cardiac arrest: a prospective study in the Netherlands," The Lancet, vol. 358, no. 9298, pp. 2039-2045, 2001.

[18] J. Levin and B. H. Kaplan, "The sorokin multidimensional inventory of love experience (SMILE): development, validation, and religious determinants," Review of Religious Research, vol. 51, no. 4, pp. 380-401, 2010.

[19] A. L. Ai, T. N. Tice, and C. L. Kelsey, "Coping after 9/11: deep interconnectedness and struggle in posttraumatic stress and growth," in The Impact of 9/11 on Psychology and Education: The Day That Changed Everything? M. Morgan, Ed., pp. 115138, Palgrave Macmillan, New York, NY, USA, 2009.

[20] A. L. Ai, K. L. Ladd, C. Peterson, C. Cook, M. Shearer, and H. G. Koenig, "Long-term adjustment after surviving open-heart surgery: the effect of using prayer for coping replicated in a prospective design," The Gerontologist, vol. 50, no. 6, pp. 798809, 2010.

[21] V. E. Frankl, Man's Search for Meaning, vol. 85, Touchstone, New York, NY, USA, 1959.

[22] K. I. Pargament, "The bitter and the sweet: an evaluation of the costs and benefits of religiousness," Psychological Inquiry, vol. 13, no. 3, pp. 168-181, 2002.

[23] K. I. Pargament, G. G. Ano, and A. B. Wachholtz, "The religious dimension of coping: advances in theory, research, and practice," in The Handbook of the Psychology of Religion and Spirituality, R. F. Paloutzian and C. L. Park, Eds., pp. 479495, Guilford Press, New York, NY, USA, 2005.
[24] G. G. Ano and E. B. Vasconcelles, "Religious coping and psychological adjustment to stress: a meta-analysis," Journal of Clinical Psychology, vol. 61, no. 4, pp. 461-480, 2005.

[25] A. L. Ai, C. Park, B. Huang, W. Rodgers, and T. N. Tice, "Psychosocial mediation of religious coping styles: a study of short-term psychological distress following cardiac surgery," Personality and Social Psychology Bulletin, vol. 33, no. 6, pp. 867-882, 2007.

[26] M. C. Luzzatto, The Way of God, Feldheim Publishers, Jerusalem, Israel, 6th edition, 1997, (Translated by A. Kaplan).

[27] P. C. Hill and K. I. Pargament, "Advances in the conceptualization and measurement of religion and spirituality: implications for physical and mental health research," American Psychologist, vol. 58, no. 1, pp. 64-74, 2003.

[28] P. C. Hill and K. I. Pargament, "Advances in the conceptualization and measurement of religion and spirituality: implications for physical and mental health research," American Psychologist, vol. 58, no. 1, pp. 64-74, 2003.

[29] R. M. Baron and D. A. Kenny, "The moderator-mediator variable distinction in social psychological research: conceptual, strategic, and statistical considerations," Journal of Personality and Social Psychology, vol. 51, no. 6, pp. 1173-1182, 1986.

[30] A. L. Ai, J. P. Bjorck, H. Appel, and B. Huang, "Asian American spirituality and religion: inherent diversity, uniqueness, and long-lasting psychological influences," in The APA Handbook of Psychology, Religion, and Spirituality, Vol. II, K. Pargament, A. Mahoney, and E. Shafranske, Eds., American Psychological Association, Washington, DC, USA, (in revision).

[31] K. I. Pargament, The Psychology of Religion and Coping: Theory, Research, and Practice, Guilford Press, New York, NY, USA, 1997.

[32] A. L. Ai, T. N. Tice, C. Peterson, and B. Huomg, "Prayers, spiritual support, and positive attitudes in coping with the September 11 national crisis," Journal of Personality, vol. 73, no. 3, pp. 763-792, 2005.

[33] A. L. Ai, S. F. Bolling, and C. Peterson, "The use of prayer by coronary artery bypass patients," International Journal for the Psychology of Religion, vol. 10, no. 4, pp. 205-220, 2000.

[34] L. S. Radloff, "The CES-D scale: a self-report depression scale for research in the general population," Applied Psychological Measurement, vol. 1, pp. 385-401, 1977.

[35] G. D. Zimet, S. S. Powell, G. K. Farley, S. Werkman, and K. A. Berkoff, "Psychometric characteristics of the multidimensional scale of perceived social support," Journal of Personality Assessment, vol. 55, no. 3-4, pp. 610-617, 1990.

[36] M. F. Scheier and C. S. Carver, "Optimism, coping, and health: assessment and implications of generalized outcome expectancies," Health Psychology, vol. 4, no. 3, pp. 219-247, 1985.

[37] C. R. Snyder, C. Harris, J. R. Anderson et al., "The will and the ways: development and validation of an individual-differences measure of hope," Journal of Personality and Social Psychology, vol. 60, no. 4, pp. 570-585, 1991.

[38] L. M. Chatters, J. S. Levin, and R. J. Taylor, "Antecedents and dimensions of religious involvement among older black adults," Journals of Gerontology, vol. 47, no. 6, pp. S269-S278, 1992.

[39] A. L. Ai, C. Peterson, S. F. Bolling, and H. Koenig, "Private prayer and optimism in middle-aged and older patients awaiting cardiac surgery," The Gerontologist, vol. 42, no. 1, pp. 70-81, 2002.

[40] K. I. Pargament, B. W. Smith, H. G. Koenig, and L. Perez, "Patterns of positive and negative religious coping with major 
life stressors," Journal for the Scientific Study of Religion, vol. 37, no. 4, pp. 710-724, 1998.

[41] J. Levin, "Prayer, love, and transcendence: an epidemiologic perspective," in Religious Influences on Health and Well-Being in the Elderly, K. W. Schaie, N. Krause, and A. Booth, Eds., pp. 69-95, Springer, New York, NY, USA, 2004.

[42] A. L. Ai, P. Wink, T. N. Tice, S. F. Bolling, and M. Shearer, "Prayer and reverence in naturalistic, aesthetic, and socio-moral contexts predicted fewer complications following coronary artery bypass," Journal of Behavioral Medicine, vol. 32, no. 6, pp. 570-581, 2009.

[43] J. S. Levin and R. J. Taylor, "Age differences in patterns and correlates of the frequency of prayer," The Gerontologist, vol. 37, no. 1, pp. 75-88, 1997.

[44] C. L. Park, M. A. Brooks, and J. Sussman, "Dimensions of religion and spirituality in psychological adjustment in older adults living with congestive heart failure," in The Role of Faith in the Well-Being of Older Adults: Linking Theories with Evidence in an Interdisciplinary Inquiry, A. Ai and M. Ardelt, Eds., Nova Science Publishers, Hauppauge, NY, USA, 2009. 


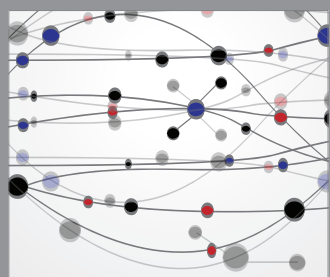

The Scientific World Journal
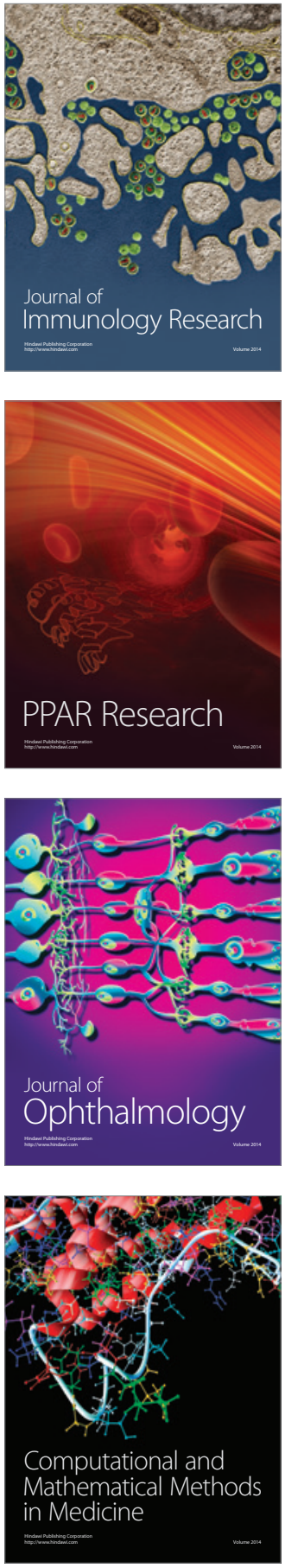

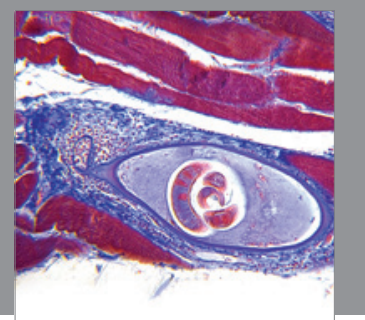

Gastroenterology

Research and Practice
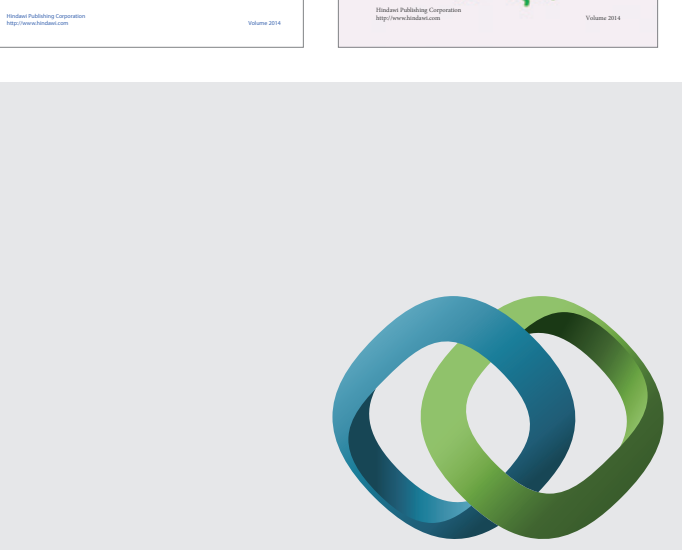

\section{Hindawi}

Submit your manuscripts at

http://www.hindawi.com
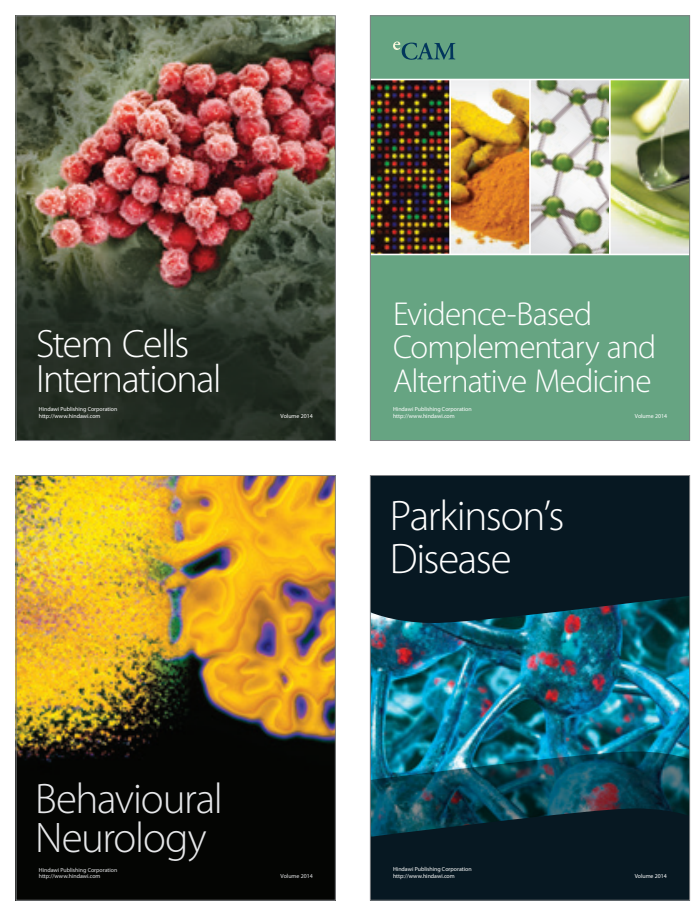

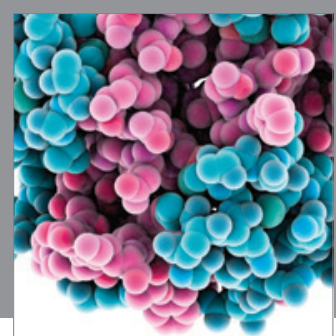

Journal of
Diabetes Research

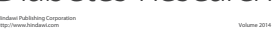

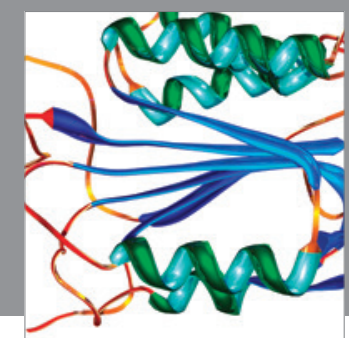

Disease Markers
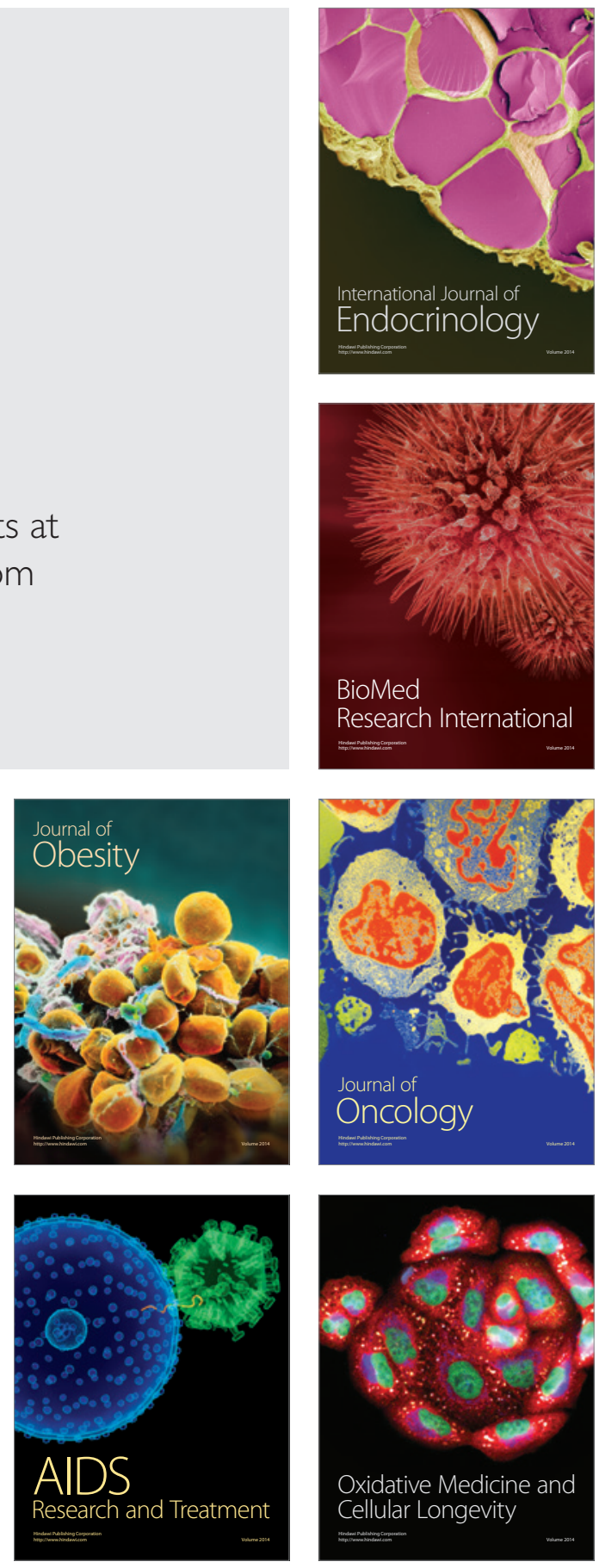